\title{
EXPERIMENTAL INVESTIGATIONS ON THE BEHAVIOUR OF PPFRC AND SFRC
}

\author{
R. Thiyagarajan \\ Teaching Fellow, Division of Structural Engineering, College of Engineering Guindy, \\ Anna University, Chennai, Tamil Nadu, India \\ Dr. K. C. Pazhani \\ Professor, Division of Structural Engineering, College of Engineering Guindy, \\ Anna University, Chennai, Tamil Nadu, India
}

\begin{abstract}
Concrete is a versatile material used in the construction industries duringthe past few decades because of its workabilityto cast into any shape using formworks. Cement is nowadays commonly available throughout the world with the recent advancements in manufacturing technology. Reinforced Cement Concrete has gained popularity as the best suited structural material in the construction industry. Fibre Reinforced Cement Concrete is gaining popularity with its inherent advantages likeenhanced tensile strength and toughness when compared with conventional reinforced cement concrete. Lightweight Concrete ( $L C)$ is also gaining importance in the recent years for several structural applications due to its advantages like reduced dead weight of components, low handling costs havingenhancedmechanical and durability properties.

The polypropylene fibres were subsequently improved intoshort fibrillated materials in the construction industries. The polypropylene is a high molecular weight material acquired from monomer C3H6 which is completely a hydrocarbon.PPF has a normal atomic arrangement in the polymer molecule and is also highlycrystalline. It is grasped as isotactic polypropylene PPF resistant To contact with more destructive chemicals, its hydrophobic surface not being wet by cement paste accommodates to hold-off chopped fibres from balling effect while mixing like other fibres. The familiarization devises the film weak in the lateral direction which promotes fibrillation. The cement matrix can enter in the mesh structure between the individual fibrils and create a mechanical bond amongst cement matrix and fibre.

The American Society for Testing and Materials published ASTM A-820 code provision is available for steel fibres. Deformed steel fibres provide a good mechanical bond within the concrete matrix to withstand pull-out. Steel fibresmainly transform the brittle concrete into a ductile one. Catastrophic failure of concrete is practically reduced. Steel fibres are added in the concrete matrix duringthe mixing of its constituent ingredients. Its main advantage is, decrease the steel reinforcement requirements, Overcome crack widths, Improve impact resistance, abrasion resistance, and freezethaw effects.
\end{abstract}

Key words: polypropylene fibres, Deformed steel fibres, Catastrophic failure, impact resistance, compressive strength, flexure and tensile strength. 
Cite this Article: R. Thiyagarajan, Dr. K. C. Pazhani, Experimental Investigations on the Behaviour of PPFRC and SFRC, International Journal of Advanced Research in Engineering and Technology, 10 (3), 2019, pp 194-202.

http://iaeme.com/Home/issue/IJARET?Volume=10\&Issue=3

\section{INTRODUCTION}

Reinforced Concrete has excellent endurance to compression while steel has more stability in tension. Traditional reinforced cement concrete has inadequate ductility, low impact and abrasion resistance and offer little resistance to cracking. A reliable concrete must have high strength with low permeability. Hence alternative composite materials are gaining popularity because of the enhancement in the durability and ductility of hardened concrete. The addition of short, irregular discrete fibres in the fresh concrete improves structural behaviour of hardened concrete in terms of cracking pattern. The addition of steel or polypropylene fibres in fresh concrete enhances the tensile strength, fracture strength, toughness, impact resistance, flexural strength resistance, fatigue performance etc. The ductility of fibre reinforced concrete is enhanced due to the ability of the fibres to bridge cracks at high levels of loading

\section{OBJECTIVES AND SCOPE OF THE RESEARCH}

The following proportion was analyzed for the experimental studies.

- The compressive strength, flexure and tensile strength of M-35 grade concrete nominal mix and addition of $0.5 \%, 1 \%, 1.5 \%, 2 \%$ of PPF and SF added by weight of cement.

\section{BRIEF REVIEW OF LITERATURE}

PritiPatel (2012) reported that, to improve low tensile strength and low strain capacity of ordinary concrete, Fibre Reinforced Concrete (FRC) has been developed. Fibres are aimed to improve tensile strength, flexural strength, toughness and impact strength, to change failure mode by means of advancing post-cracking ductility, and to control cracking. Tensile strength of the composite, in connection with the stress at which matrix develops a macro-crack, will not differ for most of the conventional fibre reinforced cementitious materials. Fibre materials in various sizes, materials and shapes have been developed for use in FRC. Among these fibres, the polypropylene fibre has been one of the most successful commercially applied fibre.

Vinay Kumar Singh (2014) reported that, there was a progress of cracks due to plastic shrinkage, drying shrinkage and other reasons for variations in the volume of ordinary concrete. The development of these micro cracks lead to elastic deformation of concrete. The fibres present in the FRC act as crack arresters. When the first crack occurs across a matrix, the firm fibres resist the load. The propagation of crack will be avoided due to this action of the fibres. Failure will be gradual similar to plastic yielding.

Mehul Patel (2013) investigated that concrete may be damaged due to many reasons like freezing of ambushed water. "Mineral admixtures" have become more popular in recent times. Most well-known among the refined mechanical characteristics of Fibre Reinforced Concrete (FRC) is its superior fracture strength, toughness, impact resistance and flexural strength resistance to fatigue. The enhanced fatigue performance is one of the main reason behind the extensive use of Polypropylene Fibre Reinforced Concrete (PFRC) in pavements, bridge decks, offshore structures and machine foundation, where the composite is subjected to cyclically Varying load during its lifetime.

Milind Mohod (2015) stated that Polypropylene fibres are hydrophobic, that is they do not absorb water. Therefore, when placed in a concrete pattern they should be mixed long enough to ensure dispersion in the concrete composite. The mixing time of fibrillated or strip fibres 
should be minimum to circumvent expedient shredding of the fibres. The type of polypropylene fibre used by manufacturers for pavement applications is the collated fibrillated fibre. The length of fibre confirmed is normally bound to the nominal maximum size of aggregate in the compound. Manufacturers prescribe that the length of the fibre be greater than twice the diameter of the aggregate. This would be harmonious with past experiences with steel fibres and also with current theories on fibre dispersion and bonding. However, they do not recommend stipulating fibres for the control of cracking from external stresses, enhanced structural strength, slab thickness reduction, joint spacing reduction, or replacement of structural steel reinforcement. Monofilament fibres, according to fibre manufacturers, only afford control of cracking caused by shrinkage and thermal stresses occurring at early ages.

Murali (2017) experimentally investigated the effects of impact loading on the Flexural Strength of Fibre Reinforced Concrete. For this experiment a total of $210(100 \times 100 \times 500 \mathrm{~mm})$ specimens were prepared using hooked end steel fibres with varying volume fractions of 0.5 , 1.0 and $1.5 \%$ and aspect ratios of 50,65, and 80 The drop-weight test was used to determine the loss of flexural strength due to the influence of impact loading. From this experimental results following conclusion has been obtained.

The steel fibre volume and its aspect ratio in concrete heads to an improvement in its impact resistance. The declines in flexural strength were reduced considerably as the volume fraction and aspect ratio of fibres were increased. The best representation of concrete under impact loading was identified in the mixes $1 / \mathrm{d}=80$.

Mekala Prathap Reddy (2015) determined mechanical properties of Steel Fibre Reinforced Concrete with mineral admixtures. He used M30 grade concrete with water cement ratio of 0.45 . He determined compressive strength, tensile of steel fibre reinforced concrete with a volume fraction of $0.5 \%, 1 \%, 1.5 \%$ and an aspect ratio of 60 . These are the results gathered from that experimental investigation.

- The minimal improvement is recognized in the workability as the percentage of Fly Ash and silica fume gains.

- The density of concrete is increased as the proportion of steel Fibre increases.

- Compaction factor increases as the Steel Fibre proportion decreases. For increase, the higher percentage of Steel Fibres slump value has been reduced.

- Water admixture should add with SFRC to increase the workability of the concrete mix.

- Stiffness properties of the concrete specimens are increased because of Steel Fibres.

Sadiqul Islam (2016) evaluated plastic shrinkage and permeability of polypropylene fibre reinforced concrete. From this experiment, the plastic shrinkage and permeability of concrete have been identified by following proportions of $0.10 \%, 0.15 \%, 0.2 \%, 0.25 \%$ and $0.3 \%$ by volume of concrete with polypropylene fibre aspect ratio of 300 .

- With the increase of polypropylene fibre $(0.1-0.3 \%)$, the compressive strength of the concrete reduced by $2-10 \%$ by comparison with control mix. The Maximum tensile strength was increased at $39 \%$ with $0.1 \%$ PPF fibre

- The Plastic shrinkage cracks decreased by $50-99 \%$ related to the control specimen by addition of $0.1-0.3 \%$ fibre.

- the crack width significantly decreased by $72-93 \%$ for up to $0.25 \%$ PPF fibre and cracks around dropped with $0.3 \%$ fibre addition.

- In general, addition of $0.1 \%$ polypropylene fibre was obtained to be effective for concrete admitting compressive $2 \%$ decrease and tensile strength $39 \%$ increased. 


\section{EXPERIMENTAL INVESTIGATIONS}

The subsequent experiments were executed adopting American Society for Testing Materials (ASTM) criteria and Bureau of Indian Standards (BIS), and ACI Committee guidelines. The different tests carried out are listed below:

- Compressive strength test of concrete cubes

- Splitting tensile strength test on concrete cylinders;

- Flexural strength test of concrete prisms;

- Elastic modulus Test

\section{RESULTS AND DISCUSSION}

The behaviour of the PPFRC and SFRC under compression, flexure and splitting tensile testing is explained in detail in this chapter.

\subsection{Influence of PPF and SF on Compressive Strength}

The results of compressive strength for various PPF and SF mix M35 grade concrete are presented in Figure 4.1. For determining the strength of M35 grade concrete, three control mix specimens were tested by the Compressive Testing Machine (CTM). Achievement of the target mean strength has been compared with mix design calculation. It is evident from the experimental studies that the 28th-day compressive strength of M35 Grade control mix is 43.4 $\mathrm{MPa}$. These results exhibit the mix design followed by manual calculation has been efficiently achieved.

The testing results of PPF mixed with traditional concrete (M35) gave effective resistance to the axial load application. The compressive strength of mixed proportion of $0.5 \%, 1 \%$, $1.5 \%, 2 \%$ PPF with M-35 grade concrete is 50.2, 54.42, 55.54 and $50.61 \mathrm{MPa}$ respectively. It is seen that the compressive strength of concrete increased compared with the M 35 grade control mix. For every increment of fibre in the concrete the strength gradually increased in a steady manner up to $1.5 \%$ PPF in the concrete mix. Similar strength variation was reported by Mustapha Abdulhadi (2014), Sathe (2013) and SaeidKakooei (2011)

Whenever the concrete cube reached an ultimate compressive strength, all the four exposed faces cracked relatively in same manner. The PPF mix with concrete reduced the aggregate interlock failure. The volume of fibre mixed with the traditional concrete formed an interfacial bond between aggregates. The plane of stress increases bulging effect around the center core of the cube specimen. Mainly due to the increase in the state of stress concentration around the concrete constituents surfaces it leads to the separation of inert particles in the transition zone. The presence of fibre around that zone made a comfortable interlock within it. The micro volume fraction of PPF and also its length provides bonding between disintegrated concrete ingredients. This theoretical reason is behind delaying the collapse of the concrete cube. Similarly, strain energy observed in the concrete mix also increased.

From the figure. 1, it can be seen that the compressive strength of Steel fibre in the M35 concrete mix provides lower strength compared with PPFRC. These are the values obtained from the experimental investigation on SF. For SF $0.5 \%, 1 \%, 1.5 \%, 2 \%$ in the volume fraction of concrete mix strength achieved was47.5,48.94,53.41,49.42MPa. The percentage of variation as compared with the traditional concrete mix is $9.44 \%$ with $0.5 \%$ SF. It clearly shows that the strength increased little bit due to the fibre present in that mix, even though this value is lesser than $2.7 \%$ with the same proportion PPF in the concrete. 


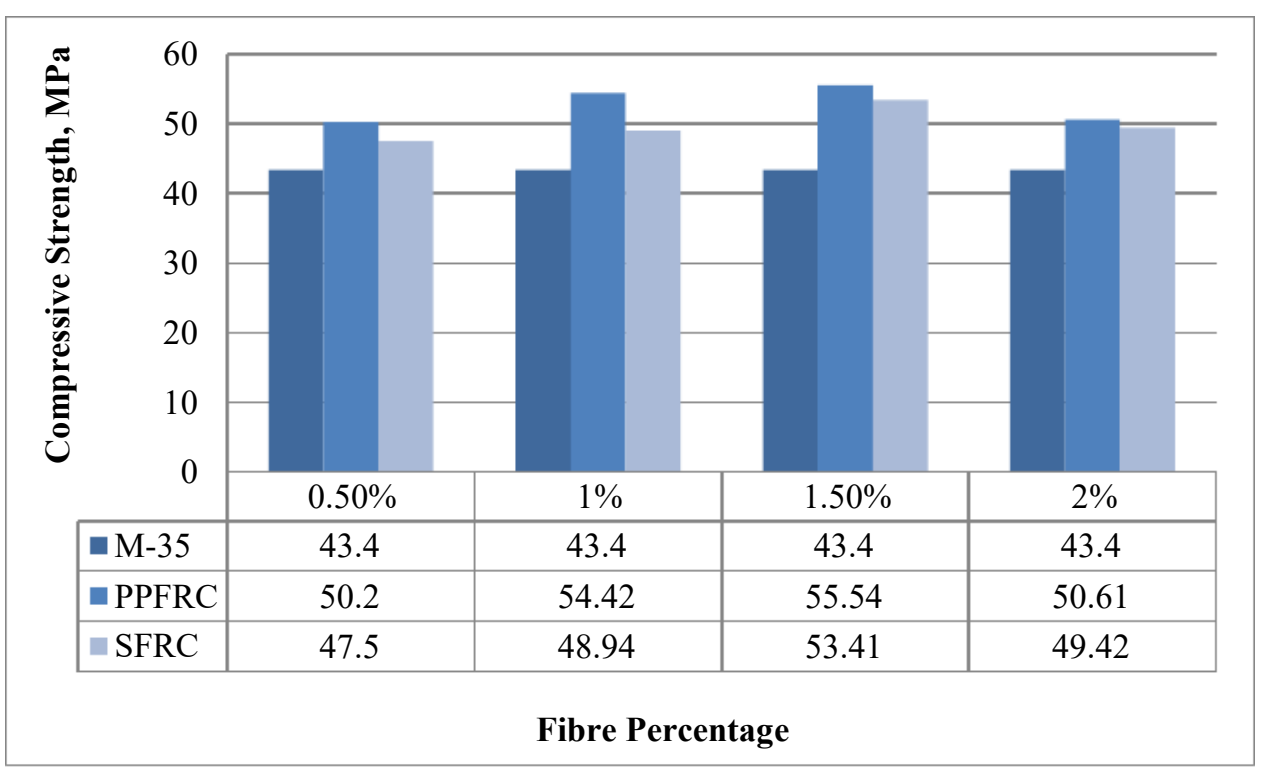

Figure. 1. Compressive strength variation of M-35 PPFRC and SFRC

The cross-sectional area of steel fibre is relatively high so its occupied area is also less. In this situation, the observed tensile stress in the fibre mingled with the concrete ingredient has the higher proportion. Moreover, the initial strain energies observed in the PPFRC are higher than SFRC. Similarly, the strength of SF 1\% with M35 concrete increased $12.76 \%$ and 13.87 $\%$. The peak value of compressive strength of steel fibre reached is $23.5 \%$ at the $1.5 \%$ of SF mix in the concrete. Kiran Kumar (2016) also reported the same proportion in his research. But it is also lesser than $1.5 \%$ of PPFRC. The comparative results of SF with PPF are $2.13 \%$ lesser. But at this optimum percentage of PPF fibre shows some advanced strength in the compression. The strength variation mainly impacts of an area occupied by steel fibre in the concrete mix as relatively lower than PPF. Also, whenever the fibre volume increase over than optimum percentage $1.5 \%$ in the concrete mix moderately the strength also decreases. This comparison shows that $1.5 \%$ of the upper limit proportion in the M35 concrete gives the higher strength. Similar variation is reported by Mustapha Abdulhadi (2014), Machine Hsie (2008) in their research. Moreover, the compressive strength increased $12.5 \%$ compared with the M35 Control mix.

\subsection{Influence of PPFRC and SFRC on splitting tensile Strength}

The results of splitting tensile strength for M35 grade concrete PPF mixes are presented in Figure. 2. It is seen that the 28-day strengths obtained for $150 \mathrm{X} 300 \mathrm{~mm}$ cylinder specimens vary from 4.61 to $4.97 \mathrm{MPa}$. From the experimental data $0.5 \% \mathrm{PPF}$ by weight of cement concrete cylinder has enhanced strength up to $7.38 \%$, similarly $1 \%, 1.5 \%, 2 \%$ variation of PPF concrete strength increased by $11.93 \%, 13.01 \%$, and $7.8 \%$ respectively. The above results clearly, showed that $1.5 \%$ addition of fibre to the concrete gave significant effect.

Also for the M35 grade concrete with SF mix the strength variation appeared in the control mix and percentage variation of steel fibre is as follows. They are $4.52 \%, 5.38 \%, 11.46 \%$ and $10.59 \%$ for $0.5 \%, 1 \%, 1.5 \%, 2 \%$ SF respectively with the weight of cement. Due to the application of load, the cylindrical specimen tends to separate but the fibre matrix reduced that formation in the concrete. Jingjun Li (2017) also reported the same increase with PPF and SF. 
Experimental Investigations on the Behaviour of PPFRC and SFRC

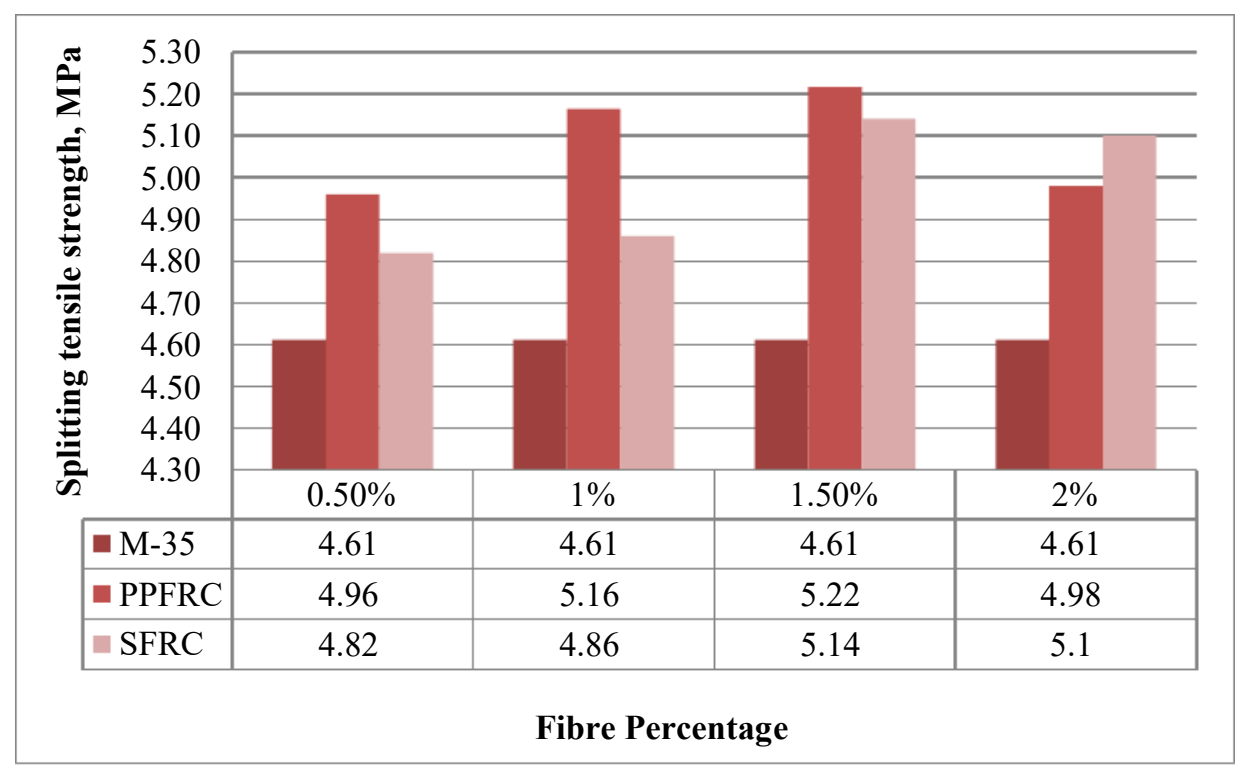

Figure 2 Splitting Tensile Strength Variation of M35 PPFRC and SFRC

The tensile strength of the fibre reinforced concrete considerably reduced the failure stage of the specimen. The comparative variation of the SFRC and PPFRC in the M35 grade, PPF behaves better under tensile strength. This significant comparative statement among them shows as $4.52 \%, 5.38 \%, 11.46 \%$ and $10.59 \%$ for $0.5 \%, 1 \%, 1.5 \%, 2 \%$ cement Weight proportion of SF and PPF with different specimens of M35 grade concrete. The maximum upper limit strength as $13.12 \%$ for M35 grade concrete at 1.5\% PPF. Aamer Bhutta (2016) also predicted on his experimental investigation on splitting tensile strength of PPFRC and SFRC. Even though the comparative results show probably these values are nearer to each other due to the tensile strength of fibres, whenever the fibre reaches optimum percentage then the flexural strength decreased due to excessive fibres in the matrix.

\subsection{Flexural strength behavior of PPFRC and SFRC}

The results of flexural strength tests for various M 35 grade mixes with PPF and SF are presented in Figure. 3. It can be seen that the 28-day strength of M 35 grade concrete with PPF in 100 X 100 X $500 \mathrm{~mm}$ Prism specimens vary from 7.10 to 8.4 MPa. From the experimental data, $0.5 \%$ PPF by weight of cement has strength increase up to $14.51 \%$, similarly $1 \%, 1.5 \%$, $2 \%$ of PPF have strength increase of $25.81 \%, 40.32 \%, 35.48 \%$ respectively. From the above results, it shows $1.5 \%$ addition of PPF to the concrete gave significant effect. The results obtained are in line with that of the results reported by BensaidBoulekbache (2016)..Also for the M 35 grade concrete mix with SF following strength variation have been obtained. They are $11.129 \%, 23.871 \%, 36.93 \%$ and $37.09 \%$ for $0.5 \%, 1 \%, 1.5 \%$, and $2 \%$ ofSF to the weight of cement. From The above result it can be seen that only smaller variation appears amid SF and PPF. The high yield strength of fibre provides the greater efficiency in the braking zone of the test beam specimen. PitiSukontasukkul (2017), Aamer Bhutta (2016) have predicted similar behaviour on flexural strength of PPFRC and SFRC. 


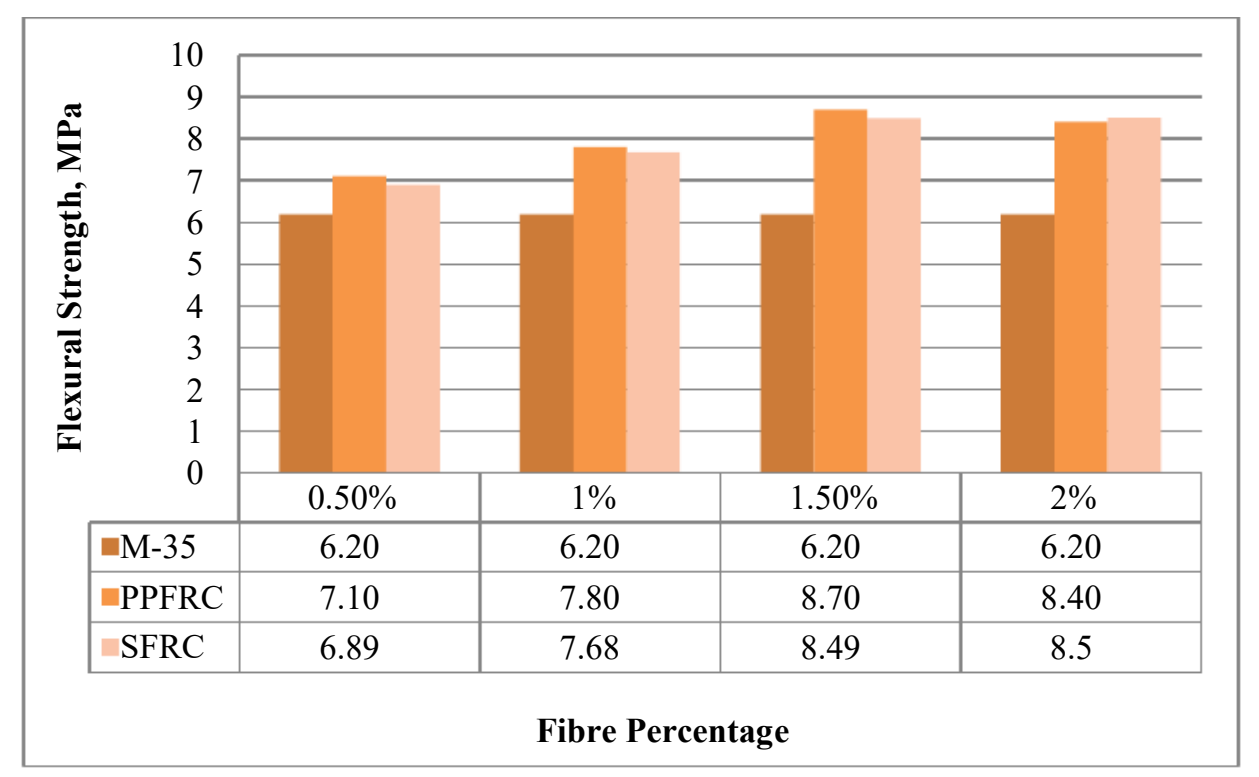

Figure 3 Flexural Strength Variation of M35 PPFRC and SFRC

\subsection{Influence of PPF and SF on Elastic modulus Test}

The modulus of elasticity was determined after curing for 28 days from the date of the casting of the test specimen. The results obtained from the elastic modulus test for controlled concrete and for mixes with PPF and SF are shown in Figure. 4. The elastic modulus of control specimen is $32939 \mathrm{MPa}$ whereas the $\mathrm{E}$ value of concrete mix with $1.5 \% \mathrm{PPF}$ is $35399 \mathrm{MPa}$. This value is comparatively higher than similar SF mix. The possible reason for this high value of elastic modulus could be widespread monofilament of polypropylene fibre in the concrete mix. It delays the development of peak tensile stress values so that the relative crack progress is also reduced. This may be the reason behind improved E value of the concrete mix. For all other mixes the modulus of elasticity of the SF mix is lower than that of the PPF mix.

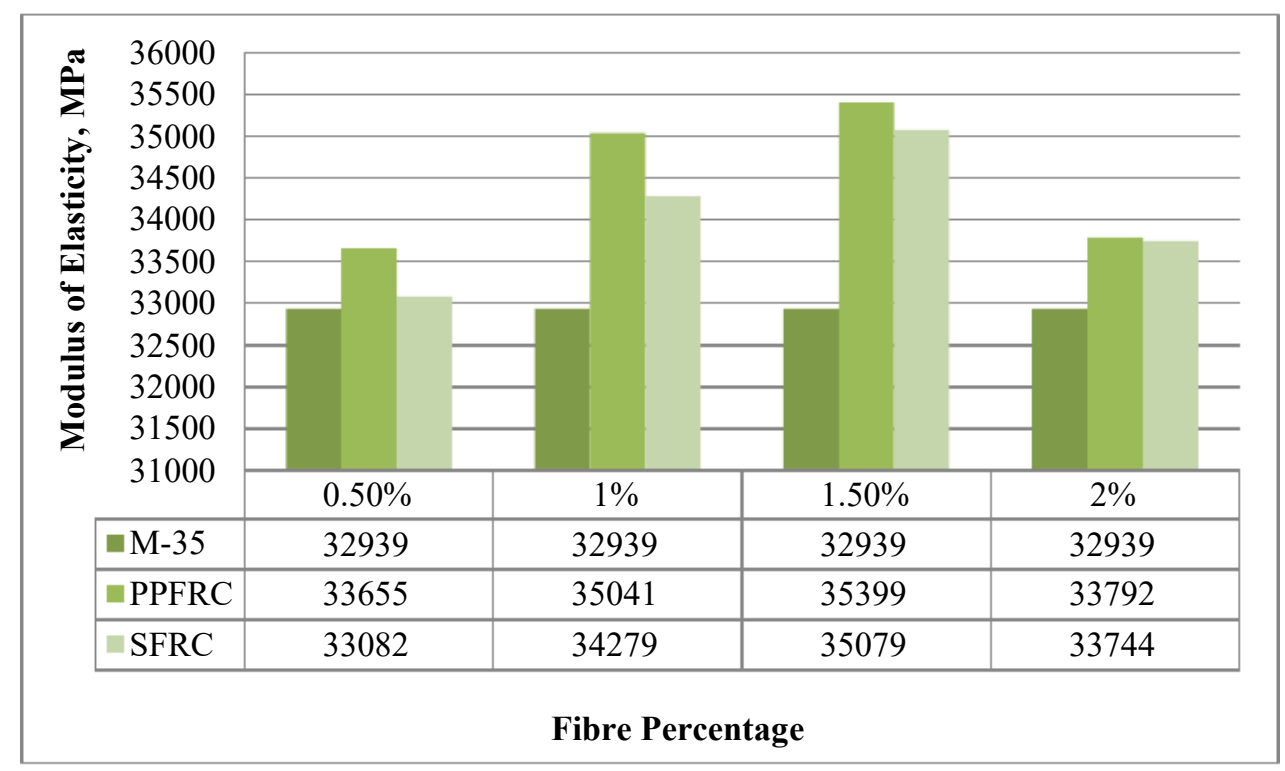

Figure 4 Modulus of elasticity Variation of M35, PPFRC and SFRC

From the experimental investigations it can be clearly seen that early strength is achieved only by the mix with $1.5 \%$ of PPF. The elastic modulus value of SFRC is relatively very low and is not effective when compared with SFRC. PitiSukontasukkul (2017) also reported similar 
results PPF and SF. In further experimental investigations using T beams, PPFRC with $1 \%$ and $1.5 \%$ of PPF will be considered.

\section{CONCLUSION}

The following conclusions are drawn from this limited experimental investigation.

- From the experimental investigations it can be clearly seen that the addition of polypropylene fibres in the fresh concrete mix enhances the strength behavior to a considerable limit.

- The ultimate compressive strength of steel fibre reinforced concrete was 53.41 MPawith 1.5 $\%$ of SF in the M35 grade concrete. It was observed that there is a decrease in the strength properties further addition of the fibres. Due to the addition of fibres, there is increase of around $23.06 \%$ in compressive strength compared with controlled concrete.

- It can be seen that the compressive strength of PPFRC is higher than SFRC concrete. The optimum percentage for addition of fibres in the concrete was found to be $1.5 \%$ with a compressive strength of 55.54MPa for M35 grade concrete. The increase in the compressive strength compared with conventional concrete was around $27.97 \%$.

- The splitting tensile strength of $1.5 \% \mathrm{PPF}$ and SF in the M35 Grade concrete was found to be $5.22 \mathrm{MPa}$ and $5.14 \mathrm{MPa}$ respectively. From the experimental investigations it can be seen that there was an increase in flexural strength of around $40.32 \%$ for PPFRC and $36.93 \%$ for SFRC when compared with control mix. The optimum percentage of addition of fibres in the concrete was found to be 1.5 .

- It can be seen that there was an increase in modulus of elasticity of around $7.46 \%$ for PPFRC and $6.49 \%$ for SFRC when compared with control mix.

\section{REFERENCES}

[1] Priti A Patel, Atul K Desai \& Jatin A Desai 2012, 'Evaluation of engineering properties for polypropylene fibre reinforced concrete', International Journal of Advanced Engineering Technology, E-ISSN 0976-3945, IJAET, vol.iii, issue 1, pp. 42-45.

[2] Vinay Kumar Singh 2014, 'Effect of polypropylene fibre on properties of concrete', International Journal of Engineering Sciences \& Research Technology, ISSN: 2277-9655, Scientific Journal Impact Factor: 3.449, pp. 312-317.

[3] Dr. B. Damodhara Reddy, N. Kiran Kumar, S. Aruna Jyothy and K. Gopinath Reddy, Experiemental Investigation of Strength and Durability Properties of Concrete with Granite Powder and Polypropylene Fibre, International Journal of Civil Engineering and Technology, 9(8), 2018, pp. 646-653.

[4] Mehul J Patel \&Kulkarni, SM 'Effect of polypropylene fibre on the high strength concrete', Journal of Information, Knowledge and Research in Civil Engineering,ISSN:09756744,vol.2,no.2,pp. 125-129

[5] Milind V Mohod 2015, 'Performance of polypropylene fibre reinforced concrete', IOSR Journal of Mechanical and Civil Engineering (IOSR-JMCE) E-ISSN:2278-1684, P-ISSN:2320-334x, vol. 12, no.1, ver. 1, pp. 28-36.

[6] J.Philips and R.Rashmi Mano, Experimental Investigation on Mechanical Properties of Polypropylene Fibre Incorporated Concrete with Silica Fume. International Journal of Civil Engineering and Technology, 7(5), 2016, pp.09-16.

[7] G Murali, VR Ramkumar, K Karthikeyan 2017, 'The Effects of Impact Loading on the Flexural Strength of Fibre Reinforced Concrete', NISCAIR-CSIR, ISSN: 0975-1084 (Online); 00224456 (Print), JSIR Vol. 76(12), pp. 790-794 
[8] P. Jagannathan and Herenz Nidhi, Analysis to Identify the Prevailing Causes that Leads to Arbitration in Construction Contracts. International Journal of Civil Engineering and Technology, 8(5), 2017, pp. 01-07.

[9] Mekala Prathap Reddy, Chandrasekhar Reddy 2015, 'Determination of mechanical properties of steel fiber reinforced concrete with mineral admixture' International Journal \& Magazine of Engineering Technology, Management and Research (IJMETMR), ISSN 2320- 3706, Vol. 2, Issue No: 4, PP. 604-610.

[10] Nanditha Mandava, Kallempudi Murali, M. Srinadh Reddy, M Narendranatha Reddy, Investigation of Reinforced Concrete Beams by Incorporating Polypropylene Fibre Reinforced Polymer Composites. International Journal of Civil Engineering and Technology, 9(1), 2018, pp. $423-430$

[11] Sadiqul Islam, Sristi das gupta 2016, 'Evaluating plastic shrinkage and permeability of polypropylene fiber reinforced concrete', International Journal of Sustainable Built Environment, ISSN: 2212-6090, pp. 1-10.

[12] A. Sofi, Raghav Sinha and Shouvik Bhattacharya, Mechanical Properties of Concrete Containing Polypropylene Fibre and Silica Fume, International Journal of Civil Engineering and Technology, 8(7), 2017, pp. 143-151.

[13] Saeid Kakooei a , Hazizan Md Akil b, Morteza Jamshidi c \& Jalal Rouhi 2012, 'The effects of polypropylene fibers on the properties of reinforced concrete structures', Elsevier, Construction and Building Materials, ISSN 0950 - 0618, Vol. 1, pp. 73-77.

[14] Shivaraj. K, George.Y \& Sokke, 1989, 'Flexural fatigue strength endurance limit and impact strength of the fibre reinforced refractory concretes, Fibre reinforced cements and concretes recent developments edited by R. N. Swamy, ISBN, 1-85166-415- 7, PP.261-273.

[15] R. Thiyagarajan and K. Nagamani, Strength Enhancement of Reinforced Concrete Flanged Beams by Polypropylene Fibres. International Journal of Advanced Research in Engineering and Technology, 8(6), 2017, pp 42-54.

[16] Vinay Kumar Singh 2014, 'Effect of polypropylene fibre on properties of concrete', International Journal of Engineering Sciences \& Research Technology, ISSN: 2277-9655, Scientific Journal Impact Factor: 3.449, pp. 312-317. 